\title{
The role of the practice educator in supporting nursing and midwifery students' clinical practice learning: An appreciative inquiry
}

\author{
Elaine Maxwell *1, Sharon Black², Lesley Baillie ${ }^{2}$ \\ ${ }^{1}$ London South Bank University, London, United Kingdom \\ ${ }^{2}$ Faculty of Health \& Social Sciences, University of Bedfordshire, United Kingdom
}

Received: August 29, 2014

DOI: $10.5430 /$ jnep.v5n1p35
Accepted: October 13, $2014 \quad$ Online Published: October 23, 2014

URL: http://dx.doi.org/10.5430/jnep.v5n1p35

\begin{abstract}
High quality, supportive practice learning experiences are crucial for ensuring that student nurses and midwives develop into competent practitioners who are fit for practice. The practice educator role is one model of practice learning support but the role is relatively new and has been little investigated. This paper reports on an appreciative inquiry that explored the current practice educator role at one university in England, with the aim of reaching a consensus for how the role could be enhanced. The first phase involved in-depth interviews with 18 participants: practice educators $(n=10)$; student nurse representatives ( $\mathrm{n}$ $=5$ ) and practice based education leads $(n=3)$. The interviews were analysed thematically. Three themes related to social processes involved in the role: being a bridge, being there, and social identity. The other themes described contributions to the practice learning environment: safeguarding, support, critical thinking. The second phase used a modified Delphi technique. Participants ranked trigger statements, related to the themes, in order of importance. Two consensus workshops were held where the statements were reviewed by practice educators, students and learning environment leads, following which principles and practices of the practice educator role were agreed. In conclusion, the strength of the practice educator role is that it bridges the worlds of university and practice. This bridging resulted from social processes that required a sustained presence in practice to engage in the reality of everyday practice and gain the shared social identity of a practitioner.
\end{abstract}

Key Words: Practice learning, Practice educator, Appreciative inquiry

\section{Introduction and background}

\subsection{Introduction}

In the United Kingdom (UK), student nurses and midwives spend $50 \%$ of their course time in practice. ${ }^{[1,2]}$ The practice setting is therefore an essential part of students' education $^{[3,4]}$ and high quality and supportive practice learning experiences are crucial for ensuring fitness for practice at the point of registration. This is not a new idea and can be traced back to Florence Nightingale who instructed that stu- dent nurses should be trained under the direct supervision of experienced nurses who were 'trained to train' ${ }^{[5]}$ However, the move to graduate only preparation for nursing in the $\mathrm{UK}^{[6]}$ has placed renewed emphasis on how the practice element can meet the standards of academic rigour as well as enabling clinical skills and competence in practice. In addition, practice placements influence students' perceptions and expectations of nursing, with unsatisfactory placement experiences and lack of support being shown to contribute to student nurse attrition. ${ }^{[7]}$

*Correspondence: Elaine Maxwell; Email: maxwele2@1sbu.ac.uk; Address: London South Bank University, London, United Kingdom. 
Currently in the UK, the practice element is supervised and assessed by registered nurses or midwives who have undergone additional approved training in order to take on the role of mentor. ${ }^{[1]}$ These mentors are employees of the practice organisation and their educational role is in addition to their clinical responsibilities. Universities that provide nursing and midwifery courses must therefore ensure that there is support for both students and their mentors in order to achieve the optimum practice experience. Whilst there are various options for achieving this, one model of support is the practice educator (PE) role. This paper presents findings from an exploration of the PE role as developed at one university.

\subsection{Support for nursing and midwifery students in clinical practice placements}

Clinical practice staff who take on the role of mentors have a crucial role in supporting student nurses and midwives to develop their competence. However, there continue to be concerns about the way in which mentors are prepared and subsequently supported. ${ }^{[8-10]}$ The UK's professional regulator for nursing and midwifery, the Nursing and Midwifery Council, requires nursing and midwifery lecturers to take on the support of both students in practice and their mentors through a 'link tutor' role. However, the lack of support provided by university staff, particularly when students are failing assessments in practice settings, has previously been criticised. ${ }^{[11-14]}$ There have been suggestions that there are insufficient numbers of university staff to support mentors and practice learning, ${ }^{[15]}$ that their insufficient presence in practice can leave some mentors feeling vulnerable ${ }^{[16,17]}$ and that input provided by link tutors is often instigated by specific issues in practice ${ }^{[18]}$ rather than being a developmental constant.

In addition to directly supervising their practice, mentors need to support students to demonstrate the application of their theoretical knowledge into informed clinical practice. ${ }^{[19]}$ However, mentors report that time spent supervising students conflicts with their care delivery and they find the role stressful. ${ }^{[20]}$ Unless managed, the conflicting demands placed on mentors in balancing their clinical, managerial and educational responsibilities can present challenges to the success of the role. ${ }^{[15,18,21-23]}$ Robinson et $a l .{ }^{[24]}$ described a diversity of posts, roles, relationships, responsibilities, resources and activities involved in delivering mentorship for student nurses and midwives in the UK. Roles include practice organisation employees who have a strategic overview of placement and mentor provision, senior staff within Higher Education Institution (HEIs), and the commissioners of education. The practice educator role is an example of a specific post that is focused on supporting mentors and students within the practice environment and is designed to cross the physical and cultural divide between university and practice setting.

\subsection{The role of the PE and local context for the study}

The role of PE is relatively new and is not as yet clearly defined or stabilised in theoretical or professional literature and guidelines, with the potential for role ambiguity. Role theory is described by Lynch $^{[25]}$ as a loose framework that explores how role holders attempt to harmonise the different behavioural expectations specific to a given circumstance in order to create a stable set of expectations. Work roles are specialised in terms of the expectations of behaviour or tasks to be undertaken and of the knowledge and skills required by the role holder. ${ }^{[26]}$ Roles are determined through a process in which an employee accepts an organisationally predetermined set of role behaviours. A consensus then develops around the way in which these behaviours are conducted in practice and the role becomes embedded to the extent that any contrary behaviours cause role conflict.

Jowett and McMullan ${ }^{[22]}$ suggested that roles such as PEs strengthen the link between the university and practice by being responsive, credible and accessible. In a study reviewing the support and mentorship student nurses receive in practice, Robinson et al. ${ }^{[24]}$ asserted that the high visibility of PEs in practice settings was perceived as facilitating the ease with which mentors felt able to raise problems. There was unanimity of view that supporting posts with a defined practice education remit was essential to effective mentorship.

This study took place at a university where PEs are employed by the university as academic members of staff who spend $50 \%$ of their time in the practice setting, which is a key role difference from lecturers who spend only $20 \%$ in the practice setting, to fulfil the link tutor role. The PEs promote the development of the student-mentor relationship and support the assessment process of students in practice. The role was introduced into the university ten years ago and it was considered timely to investigate the PE role as new nursing and midwifery curricula were being developed and implemented.

\subsection{Study aim}

The aim of this study was to conduct an appreciative inquiry into the role of the PE from the perspectives of PEs, students and practice learning environment representatives and to reach agreement about principles of practice for the PE role in the future.

\section{Method}

\subsection{Design}

The method used in this study was appreciative inquiry (AI). AI is a methodology that gathers positive (appreciative) ideas and images from individuals or groups as a way of fostering learning and promoting innovative ideas. ${ }^{[27]} \mathrm{AI}$ 
has been used successfully to look at a range of issues including leading in complex systems, ${ }^{[28]}$ maintaining wellbeing, ${ }^{[29]}$ improving public services ${ }^{[30]}$ and exploring quality of care. ${ }^{[31]}$ The aim of AI is to 'generate new knowledge of a collectively desired future ${ }^{,[32]}$ and it achieves this through four phases, the 4 Ds: discovery (appreciating the current status), dream (envisioning an enhanced future), design (co-constructing the route to the new future) and destiny (sustaining the change). Figure 1 portrays how AI was applied to this study.

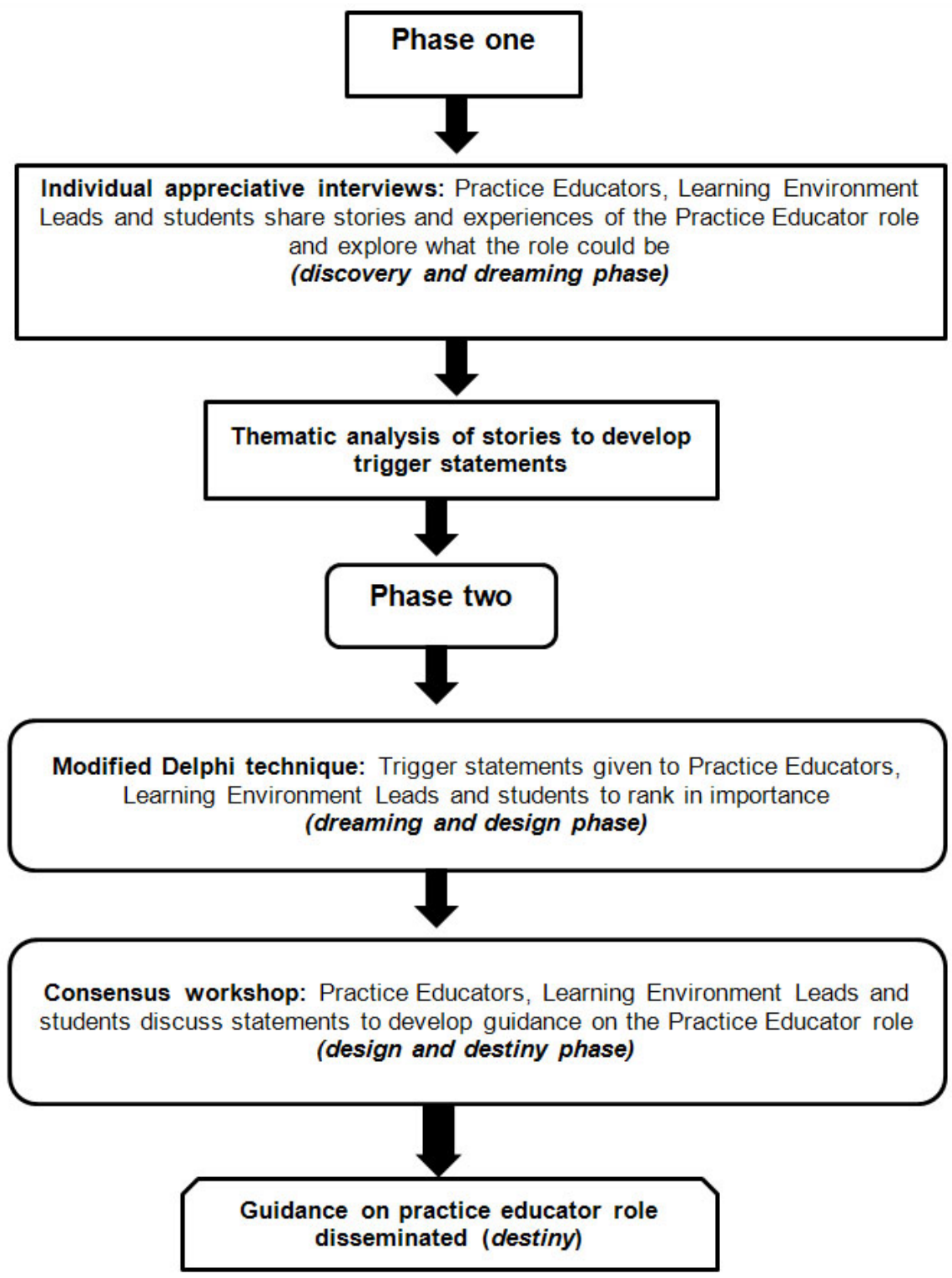

Figure 1: The AI process

\subsection{Setting and participants}

The study was based at one campus at a university in southern England, and with two of the university's partner healthcare systems (termed 'Trusts') that provide practice learning experience for nursing and midwifery students; one Trust provides acute hospital and community services (including maternity) and the other Trust provides mental health services. The total number of participants in the study was eighteen. All eleven PEs based at the campus were invited to participate and ten agreed, of which nine were nursing and one was midwifery. Student representatives $(n=12)$ from the third year nursing and midwifery cohorts were also invited and five agreed, of which four were nursing and one was midwifery. The three Learning Environment Leads (LELs), who are healthcare system employees with a specific role to support students' practice learning, all agreed to participate. 


\subsection{Data collection}

There were three stages: interviews, modified Delphi technique and a consensus workshop.

\subsubsection{Interviews}

In phase one, interviews of up to one hour were conducted with the participants (discovery and dreaming phase (see Figure 1). A semi structured schedule was used with core topics for all three groups (practice educators, students, learning environment leads) and additional specific questions for each group. Interviews with PEs focussed on exploring the experiences in which they felt most engaged, challenged and effective in their role, together with how these positive aspects of the role could be sustained. LELs were questioned on their understanding of the PE role, and what they believe makes the role effective for students and healthcare staff. Students were invited to describe their experience of the PE role and how they felt it had affected their learning. The interviews were conducted in a private interview room on the university campus and were all audiorecorded, and then transcribed and analysed thematically (see section 2.4).

\subsubsection{Modified delphi technique}

In phase 2, a modified Delphi technique for the 'dreaming' and 'design' phase (see Figure 1) was conducted with themes, identified from the interviews, that were developed into trigger statements using the participants' words. ${ }^{[33]}$ The Delphi technique is a method for structuring group communication processes to enable a group of individuals to address a complex issue. ${ }^{[34]}$ Its main strength lies in 'the achievement of consensus in an area of uncertainty where there is a lack of empirical evidence' and as a 'democratic and structured approach that harnesses the collective wisdom of participants'. ${ }^{[35]}$ The trigger statements were sent to the participants, who ranked them in order of importance, and returned their answers to the research team.

\subsubsection{Consensus workshop}

Participants were invited to a consensus workshop to complete the 'dreaming and design' phases. The ranked trigger statements were used as the basis for discussion using a nominal group technique, to develop provocative propositions. ${ }^{[33]}$ Participants discussed the trigger statements which were further developed to reach a consensus on principles and practices of the PE role, which would form the basis for developing future guidance.

\subsection{Data analysis}

The phase one interviews were read through to gain familiarity and then thematic analysis was conducted by applying codes that emerged from the data, and grouping codes into categories, from which the final themes were developed. ${ }^{[36]}$ The themes were developed into trigger statements which 38 formed the basis for the modified Delphi technique (2.3.2) and then the consensus workshop (2.3.3).

\subsection{Ethical considerations}

A University Research Ethics Committee application was approved. The PEs, LELs and student representatives were sent invitation letters, accompanied by information sheets, via email. The information sheets informed participants about consent, confidentiality, data protection, right to withdraw, potential benefits and potential harms. Participants gave written consent to participate in all parts of the study. All data were anonymous and kept securely on password protected computers. The interviewer was not an employee of the university and had no prior contact with any of the respondents.

\subsection{Rigour}

The research team addressed rigour within the research process with attention to the two key principles proposed in Meyrick's ${ }^{[37]}$ model: transparency about the research process and the use of a systematic approach. A reflexive diary and an audit trail were maintained throughout the research process, and detailed the decisions made during data collection and analysis. One researcher conducted all eighteen interviews using standardised interview schedules developed by the research team. The same researcher led the data analysis, in close collaboration with the research team, who all reviewed the transcripts and emerging themes and the draft principles of practice. The inclusion of different groups of participants (practice educators, learning and environment leads and students) enabled triangulation of data from different sources, so that the PE role could be critically reviewed from different perspectives. Member-checking took place through the participants' inclusion in the two rounds of consensus workshops, where the draft principles of practice developed from the data were critically reviewed before agreement.

\section{Results}

The results are presented in three sections: the themes that emerged from the Phase 1 interviews, the discussion statements used in the modified Delphi technique, and the principles and practices for PEs agreed through the consensus workshops.

\subsection{Phase 1 interviews}

Analysis of the phase 1 interviews yielded six core themes (see Table 1). The first three themes relate to the social processes involved in being a PE, whilst the remaining three themes describe the PEs' practice and the role's contribution to the practice learning environment. Each of these themes is next presented, illustrated with quotations from participants.

ISSN 1925-4040 E-ISSN 1925-4059 
Table 1: Themes (emerged from interviews)

\begin{tabular}{|c|c|c|}
\hline Initial main themes & Underpinning themes & Meaning \\
\hline 1. Being a bridge & $\begin{array}{l}\text { - Partnership } \\
\text {-Translation } \\
\text { - Continuity } \\
\text { - Resolving dissonance } \\
\text { - Bridging academic and practice processes }\end{array}$ & $\begin{array}{l}\text { - Between University and Trust } \\
\text { - Between University and mentors } \\
\text { - Between University and students }\end{array}$ \\
\hline 2. Being there & $\begin{array}{l}\text { - Visibility } \\
\text { - Responsiveness } \\
\text { - Compassion } \\
\text { - Picking up things } \\
\text { - Listening ear }\end{array}$ & $\begin{array}{l}\text { - Being visible } \\
\text { - Understanding the emotional labour of the } \\
\text { work }\end{array}$ \\
\hline 3. Social identity & $\begin{array}{l}\text { - Organisational identity } \\
\text { - Multiple identities } \\
\text { - Credibility } \\
\text { - Critical friend } \\
\text {-Threat to the role } \\
\text { - Progression }\end{array}$ & $\begin{array}{l}\text { - Critical friend } \\
\text { - Clinically credible } \\
\text { - Understanding emotional labour of practice } \\
\text { setting }\end{array}$ \\
\hline 4. Safeguarding & $\begin{array}{l}\text { - Practice standards } \\
\text { - Student evaluation } \\
\text { - Rescuing failing students } \\
\text { - Safe environment } \\
\text { - Safeguarding the profession }\end{array}$ & $\begin{array}{l}\text { - Safeguarding vulnerable students } \\
\text { - Safeguarding unsafe practice environments }\end{array}$ \\
\hline 5. Support & $\begin{array}{l}\text { - Student support } \\
\text { - Mentor support } \\
\text { - Trust } \\
\text { - Practice area support } \\
\text { - All ward staff }\end{array}$ & $\begin{array}{l}\text { - Pastoral support } \\
\text {-Transition to becoming a professional }\end{array}$ \\
\hline 6. Critical Thinking & $\begin{array}{l}\text { - Articulating thought processes } \\
\text { - Anchoring critical thinking in busy workplace } \\
\text { - How and why } \\
\text { - Problem solving teaching } \\
\text { - Professional and clinical thinking } \\
\text {-Transferable skills }\end{array}$ & $\begin{array}{l}\text { - Facilitating critical thinking } \\
\text { - Articulating critical thinking }\end{array}$ \\
\hline
\end{tabular}

\subsubsection{Being a bridge}

PEs were seen to occupy a unique position, bridging the academic world of the university and the practical world of the clinical placement in a way that other educational roles, such as lecturers, did not. The way in which they were perceived to bridge these different environments was by providing constancy between the two and by translating the abstract academic theory into contextualised, particular practice.

"I think that in itself is their most valuable role, the two halves of the course need to be physically linked" (Student 1)

For the staff in clinical placements it was by working in partnership to provide a learning environment.

"They [PEs] communicate directly with Learning Environment Lead and my senior staff regarding policies or student guidance; we tackle problems or challenges together to often bring forward a common sense approach. I think that, within the hospital setting or the healthcare setting, is the most valuable parts of their work." (LEL2)

Both students and placement staff felt that the two different worlds use different vocabulary, as demonstrated in the students' Practice Assessment Documents (PAD). This document was described as cognitively challenging and not immediately aligned to the expectations that placement staff have for students. The PE could support mentors and students in using the document to assess students and complete their documentation:

"My mentors were saying, although I was good in practice, I wasn't very confident and I wasn't managing things and I couldn't quite work out if I was good at doing something, so how she can mark us down and say I wasn't quite there on the PAD and so the practice educator just 
showed us how to turn it round and put it in writing, to make it more positive." (Student 2)

As well as translating, PEs also resolved the dissonance between theory and practice, helping students to understand the contextual reasons why practice does not always match expectations derived from the academic course content and the rationale behind any differences.

\subsubsection{Being there}

Being a bridge is only possible through being there to address potential difficulties as soon as possible after they arise. Visibility and immediacy of response by the PEs were seen to be very important for students and staff in the clinical placements. PEs were able to be responsive because, unlike university lecturers, they were physically present and because of the immediacy of their response PEs understood the contemporaneous emotional labour of clinical practice.

"I can walk into a shift and I can feel the stress and I can feel the pressure and I can feel when people are having a good shift." (PE3)

Students described this understanding of current demands as critical to establishing the PE's credibility, equal to if not more significant than clinical technical competence.

\subsubsection{Social identity}

The credibility conferred by being there and the bridging of the two world views gave PEs a unique identity, distinct from lecturers and from the LELs. However, while the PEs valued their practice role and identity, they did not feel this role was always recognised by the university; some gained the impression that university-based work was of higher status. They considered that the identity was more of a critical friend to the students than of a practice assessor (conducted by placement staff - the mentors) or examiner (university lecturer):

"It may only be a psychological difference but you can approach your practice educators without fear of reprisal, in the knowledge that they'll try to fix them if there's a problem" (Student 1)

As critical friends, PEs enhanced the students' learning experience through a number of activities. These involved addressing the learning outcomes of the curriculum but also covered the important activity of guiding students in developing their professional behaviour in addition to clinical skills. A number of participants noted that students need to be socialised into professional behaviour, e.g. changes in the acceptable use of social media when transitioning between private and professional roles. The PEs themselves valued their contribution to pastoral care, often assisting students who had difficulties outside their course and helping them to develop coping strategies. Students reported that this was valued but felt that extended pastoral support applied to only a small percentage of students and they would like to see this pastoral care extended to all students.

\subsubsection{Support}

Some students noted that 'no news is good news' in that the only feedback they got was to identify areas for their development. This perception however varied; some student representatives reported frequent contact with PEs while others expressed that PEs spent the majority of their time with students who were underachieving. Students who appeared to be satisfactory had little contact and did not necessarily appreciate the full range of support that PEs provided. These students felt that they would like PEs to feed back where they were achieving or indeed excelling in practice as well as where there were concerns.

\begin{abstract}
"Particularly helpful for me, quite often is just when they show their face, when they actually walk onto that ward and you think "I'm loved, it's going okay". That is hugely valuable, I don't need necessarily just for the bad bits to be tackled" (Student 1)
\end{abstract}

The LELs reported that PEs were particularly appreciated for making mentors feel valued. PEs reported that many mentors experienced the same practice-theory gap as their students; they complete theoretical preparation to be a mentor but need support in applying this to practice and contextualising this to different student needs. Both students and PEs reported that mentors often needed assistance to understand what to expect of students at different stages of their training, and that PEs pick up on mentor burnout.

\subsubsection{Critical thinking}

PEs and students felt that the support given was less about specific technical skills training and more about bridging the gap between theory and practice by encouraging critical thinking. Critical thinking was facilitated in a number of ways. PEs illuminated the thinking processes that experts use in practice. During busy shifts, students often observe excellent practice but staff do not articulate their thought processes. PEs were able to 'fill in the gaps' through reflective sessions or problem based teaching. The immediacy afforded by 'being there' means that this can be done at a time close enough to the event for the students to recall in detail and to retain the emotional connection to the event that characterises practice education. Critical thinking is further extended by reflection on the transferability of the learning to different circumstances. 
"I walked in, two student nurses had been involved in a huge trauma which had had a negative ending, so the patient had died [...] there was blood everywhere, it was in a terrible state and my two student nurses were there helping clean up this patient before the patient was going to be identified [... I I just watched the way that they behaved and then afterwards we went into the office and we debriefed on the situation [...] went through it all and at the end of it they said to me, " now we understand what happened"" (PE9)

\subsubsection{Safeguarding}

PEs' identity as critical friends who are visibly present in practice was seen to make them ideally placed to safeguard both learning environments and clinical practice standards by identifying skills deficits and recommending develop- ment opportunities. The LELs particularly valued the intelligence from experienced nurses and midwives who have prolonged contact with practice areas and are able to pick up on nuances that are not yet detected through quantitative measures. PEs were also considered to safeguard students by identifying those who needed additional support in order to successfully complete their placement before the mentor's formal assessment and to provide the support which averts the need to formally implement a structured process.

\subsection{Discussion statements (developed for modified Delphi technique, 2.3.2)}

The findings described above following thematic analysis of the interviews were developed into 20 statements using the participants' own words. These were then sent out to participants who ranked them in order of priority. The ranked statements were combined to produce an aggregated ranking (see Table 2).

Table 2: Statements about the PE role; in order of highest scoring

\begin{tabular}{|c|c|}
\hline Ranking & Statement \\
\hline 1 & Practice educators have got a foot in both camps (University and Trust) and act as a bridge \\
\hline 2 & Practice Educators are a visible presence and build relationships on behalf of the University \\
\hline 3 & Practice Educators are equal but different to lecturers \\
\hline 4 & Practice Educators work in partnership with Trust staff to tackle problems and create innovations \\
\hline 5 & $\begin{array}{l}\text { Practice Educators rescue potentially failing students and support mentors in describing the problem and } \\
\text { developing remedial plans }\end{array}$ \\
\hline 6 & Practice Educators provide an informed but independent listening ear \\
\hline 7 & $\begin{array}{l}\text { Practice Educators gain credibility through staff and students trusting that they understand the emotional work } \\
\text { involved in current clinical practice }\end{array}$ \\
\hline 8 & Practice Educators respond quickly to student or mentor concerns \\
\hline 9 & $\begin{array}{l}\text { Practice Educators help students and mentors to conduct constructive assessment and to use the Practice } \\
\text { Assessment Document positively }\end{array}$ \\
\hline 10 & Practice educators are a constant for students who are always moving to new experiences and practice areas \\
\hline 11 & Practice Educators role model expert practice thinking \\
\hline 12 & Practice Educators pick up changes in the placement area \\
\hline 13 & Practice Educators affirm when students get things right and build their confidence \\
\hline 14 & $\begin{array}{l}\text { Practice Educators challenge students to consider practice and how it relates to the Nursing and Midwifery Council } \\
\text { Code of Conduct }\end{array}$ \\
\hline 15 & Practice Educators provide pastoral support to ensure students can maintain their studies \\
\hline 16 & Practice Educators provide space in a busy environment to reflect and think critically \\
\hline 17 & Practice Educators encourage staff and students to apply rigour to their thinking \\
\hline 18 & Practice educators make mentors feel valued \\
\hline 19 & Practice Educators act as ‘thermometers’ of clinical practice culture \\
\hline 20 & Trusts identify Practice Educators as ‘one of them’ \\
\hline
\end{tabular}

\subsection{Consensus workshops: agreement of principles and practices for PEs}

Each of the twenty statements was discussed and confirmed, amended or discarded. At the end of the first workshop, a draft set of principles was agreed. At the second work- shop, the twenty statements were discussed and the principles from the first workshop were considered and amended. The final agreed consensus statement is presented in Table 3. 
Table 3: Practice Educator role: principles and practices

Practice educators are experts in current practice education and work as university representatives, in partnership with practice staff to develop applied practice, create innovations and realise excellence. They:

- $\quad$ act as a bridge between theory and practice, with an equal presence in the university and in practice

- $\quad$ work in partnership with practice staff to evaluate the culture, attitudes and professional behaviours in practice to assure the learning environment

- $\quad$ promote safety and standards by being an independent critical friend in practice and updating practitioners on current best evidence

- $\quad$ provide feedback to students and mentors that enhances practice learning

- $\quad$ are a visible presence and build relationships on behalf of the university by networking and championing best practice

- $\quad$ are a constant for students encountering new experiences, and for practice area staff, providing an informed but independent listening ear

- $\quad$ respond quickly to student or mentor enquiries

- $\quad$ coach students and mentors to conduct constructive and rigorous assessment and to use the Practice Assessment Document positively to facilitate critical thinking

- $\quad$ support students and mentors to optimise each student's potential and experience

- $\quad$ are credible and current through understanding the emotional work involved in contemporary clinical practice .

\section{Discussion}

This study explored the role of PE from the perspectives of practice educators, third year students and learning environment leads in partner healthcare systems. The study enabled the development of a common understanding of the role, both currently and for the future. Abbott ${ }^{[38]}$ described how stable role expectations are created through both having organisational jurisdiction (agreements between organisations, job descriptions) and workplace jurisdiction (agreement from co-workers about the scope of the role). Maxwell et al. ${ }^{[39]}$ demonstrated how workplace jurisdictions are dependent on a shared social identity with key co-workers in the workplace. The PEs sit between two clear identities: that of educator, and that of clinical practitioner. Establishing a workplace jurisdiction in this space requires the PEs to share both education and clinical practice identities and this was reflected in the four highest ranked statements in the Delphi round of the study. This reinforces the findings of Jowett and McMullan ${ }^{[22]}$ that practice educators are the 'missing link'. However, the PEs in this study felt that the university did not always recognise their shared identity with practice and that their role is equal to, but different from, lecturers. They were concerned that their university teaching was afforded higher status than their physical presence in the workplace and this could present a threat to the shared identity with practice that allowed the role to bridge the gap between the two.

Previous research has suggested that PEs establish their workplace jurisdiction through their clinical expertise. ${ }^{[40]}$ However, this study uncovered the critical role of sharing understanding of the emotional labour of nursing ${ }^{[41]}$ in the clinical placement. In a qualitative study re-examining the emotional labour of nursing, Gray ${ }^{[42]}$ suggests that this phenomenon is crucial to nurse patient relationship, but there is potential for this emotional labour to be abused. Therefore students should be given support, education and training to deal with these emotions, and the opportunity and space to reflect upon and manage their emotions. In this study, students reported that the PEs were able to explore and support them through the emotional demands of practice that they had not anticipated and this was distinct from the clinical skills base.

Recent inquiries into deficits in UK healthcare, such as the Public Inquiry into Mid Staffordshire NHS Trust ${ }^{[43]}$ report have highlighted the demands on nursing and the rate of burnout that can lead to a loss of compassion. Students are not immune to high levels of stress and practice placements contribute significantly to this stress. ${ }^{[4]}$ This is particularly true in the final placement when students can experience transition shock where they can feel inadequate and lack confidence in their abilities prior to qualifying as a registered nurse, and are fearful of the accountability associated with the role. ${ }^{[45,46]}$ PEs are well placed to identify these stresses and develop resilience in both students and mentors and may be required to develop a body of scholarship in this area. The study also suggested that PEs encourage the development of professional values, confirming the findings of Shinyashiki et al. ${ }^{[47]}$ and Mlinar ${ }^{[48]}$ that these develop across the three years of study.

Collington et al..$^{[49]}$ found that the fundamental aspects of the university link roles are about supporting students, participating in assessments, supporting mentors and maintaining clinical credibility. Rooke ${ }^{[50]}$ also found that partnership working and support for mentors can enhance the mentor experience particularly in the final sign-off stage of a student's practice experience. This study uncovered a wider range of role expectations than those relating to education. The concept of 'presencing', in which deliberate focused attention, receptivity to the other person, and persistent awareness of the other's shared humanity has been considered in relation to patient car ${ }^{[51]}$ but also appeared to have resonance for the students in this study. Students saw the PEs as a constant presence in practice across the three years and therefore often sought pastoral care to help them make the transition from student to professional. Morrell and Ridgway ${ }^{[52]}$ found that the support students require from mentors is over the recommended $40 \%$ as identified by the $\mathrm{NMC}^{[6]}$ and this can often result in the student feeling alone. The findings from this study suggest that PEs can bridge this gap by offering the required amount of support. 
PEs were also seen as having a responsibility for directly observing and reporting on standards in the practice area. The importance of the external view from students and educationalists in safeguarding standards in the practice environment was emphasised in the Public Inquiry into failings at Mid Staffordshire NHS Trust in England, ${ }^{[43]}$ which found that students and educationalists were aware of concerns but failed to report them to service managers. A further UK report ${ }^{[53]}$ also highlighted that students have an important role in safeguarding standards and PEs are well placed to support students to provide scrutiny and raise concerns.

The development of critical thinking skills takes time and is dependent on exposure to specific theoretical content, and the use of creative teaching and learning approaches. ${ }^{[54]}$ Critical thinking can be tested in simulation where the facilitator acts as a resource, ${ }^{[55,56]}$ probing and questioning to challenge the theoretical propositions. This study found that the PE was able to prompt critical thinking in mentors and in students in everyday situations, drawing on current evidence bases. This enabled the discussion to explore real life scenarios in which patients have complex and multiple co morbidities and where resources may not be ideal, thus preparing students for the reality of everyday practice. Having the opportunity to discuss the emotional aspects of such scenarios can improve patient care and help to reduce the theory-practice gap. ${ }^{\text {[57] }}$

\subsection{Limitations of the study}

This was a small study based at one university in England and it did not examine the role of university link lecturers on the student and mentor experience nor other possibilities for supporting practice education. The sample of student representatives was small, although participating students did reflect on the experiences of their peers as well as their own. The inclusion of other clinical practice staff could have been valuable although the learning environment leads did represent the views of staff across the healthcare system due to their roles in supporting these staff at ward and unit level.

\subsection{Recommendations for further research}

Further study is needed to develop understanding of how educational support roles, such as PEs can facilitate learning about the emotional labour of nursing, including identifying and raising concerns, as well as clinical skills development.

\section{Conclusions}

A quality practice learning experience is essential for student nurses and midwives and the PE role has potential to support both students and practice staff in mentor roles. The study enabled the development of a common understanding of the PE role and principles and practices. A wide range of ways in which PEs support students and mentors in the healthcare learning environment were identified, most of which were related to the way in which nursing is practised rather than to technical clinical skills, which remained the domain of the mentor. When PEs facilitate clinical skills learning, it is more likely to be in terms of exploring clinical decision making and relating this to the evidence base. The strength of the PE role was seen to be in their ability to bridge the two worlds of academia and clinical practice and translate the theoretical teaching delivered in the university into practice and vice versa. This bridging was the result of a number of social processes that required a sustained presence in the practice environment to ensure an understanding of the reality of everyday practice and to gain the shared social identity of a practitioner. This part of the PE role remains critical to creating effective academic/ practice partnerships and universities need to consider how best they can enable these roles to be effective.

\section{References}

[1] Nursing and Midwifery Council. Standards for pre-registration midwifery education. London, NMC [Internet]. 2009. Available from: http://www.nmc-uk.org/Documents/Standards/nm cStandardsforPre_RegistrationMidwiferyEducation.pd f (lastaccessed14thAugust 2014).

[2] Nursing and Midwifery Council. Standards for pre-registration nursing education, London, NMC [Internet]. 2010. Available from: http://standards.nmc-uk.org/PublishedDocuments/Sta ndards $\% 20$ for $\% 20$ pre-registration $\% 20$ nursing $\% 20$ educat ion\%2016082010.pdf (lastaccessed14thAugust2014).

[3] Chesser-Smyth, P.A. The lived experiences of general student nurses on their first clinical placement: A phenomenological study Nurse Education in Practice. 2005; 5(6): 320-327. PMID:19040840 http: //dx.doi.org/10.1016/j.nepr.2005.04.001

[4] Midgley, K. Pre-registration student nurses perception of the hospital-learning environment during clinical placements. Nurse Ed- ucation Today. 2006; 26(4): 338-345. PMID:16406618 http://dx .doi.org/10.1016/j.nedt.2005.10.015

[5] Myrick, F. Preceptorship: A viable alternative clinical teaching strategy? Journal of Advanced Nursing. 1998; 13(5): 588-591. http: //dx.doi.org/10.1111/j.1365-2648.1988.tb01452.x

[6] Nursing and Midwifery Council. Standards to support learning and assessment in practice. London, NMC [Internet]. 2008. Available from: http://www.nmc-uk.org/Documents/NMC-Publicati ons/NMC-Standards-to-support-learning-assessment . pdf (lastaccessed15thAugust2014).

[7] Eick, S.A., Williamson, G.R., Health, V. A systematic review of placement-related attrition in nurse education. International Journal of Nursing Studies. 2012; 49(10): 1299-309. PMID:22269138 http://dx.doi.org/10.1016/j.ijnurstu.2011.12.004

[8] Nettleton, P., Bray, L. Current mentoring schemes might be doing our students a disservice. Nurse Education in Practice. 2008; 8(3): 205-212. PMID:17959417 http://dx.doi.org/10.1016 /j.nepr.2007.08.003 
[9] Pearcey, P.A., Draper, P. Exploring clinical nursing experiences: Listening to students. Nurse Education Today. 2008; 28(5): 595601. PMID:17950499 http://dx.doi.org/10.1016/j.nedt. 2007.09.007

[10] Black, S. Being a mentor who fails a pre-registration nursing student in their final placement: understanding failure. 2011. Available from: http://www.rcn.org.uk/_data/assets/p df_file/0008/458234/Black_S_PhD_Thesis_August_2011 .pdf (Lastaccessed15thAugust2014)

[11] Allan,T. D., and Eby, L. T. Mentor commitment in formal mentoring relationships. Journal of Vocational Behavior. 2008; 72(3): 309-316. http://dx.doi.org/10.1016/j.jvb.2007.10.016

[12] Kendall-Raynor, P. Universities accused of ignoring mentors over failing 'students. Nursing Standard. 2009; 23(39): 5.

[13] Middleton, R., Duffy, K. Mentoring a student immediately prior to registration: a qualitative study. British Journal of Community Nursing. 2009; 14(11): 481-486. PMID:20166472 http://dx.doi.o $\mathrm{rg} / 10.12968 / \mathrm{bjcn} .2009 .14 .11 .45005$

[14] Gainsbury, S. Mentors passing students despite doubts over ability. Nursing Times. 2010; 106(16): 1-3.

[15] Hutchings, A., Williamson, G.R., Humphreys, A. Supporting learners in clinical practice: capacity issues. Journal of Clinical Nursing. 2005; 14(8): 945-955. PMID:16102146 http://dx.doi.org $/ 10.1111 / \mathrm{j} .1365-2702.2005 .01239 . \mathrm{x}$

[16] Luhanga, F., Yonge, O.J., Myrick, F. 'Failure to assign fail grades': issues with grading the unsafe student. International Journal of Nursing Education Scholarship. 2008; 5(1): 1-14. PMID:18384275 http://dx.doi.org/10.2202/1548-923X.1366

[17] Jervis, A., Tilki, M. Why are nurse mentors failing to fail student nurses who do not meet clinical performance standards? British journal of Nursing. 2011; 20(9): 582-587. PMID:21647023 http: //dx.doi.org/10.12968/bjon.2011.20.9.582

[18] Carnwell, R., Baker, S., Bellis, M., Murray, R. Managerial perceptions of mentor, lecturer practitioner and link tutor roles. Nurse Education Today. 2007; 27(8): 923-932. PMID:17408814 http: //dx.doi.org/10.1016/j.nedt.2007.01.005

[19] Taylor, C. A collaborative approach to developing "learning synergy" in primary health care. Nurse Education in Practice. 2007; 7: 18-25. PMID:17689420 http://dx.doi.org/10.1016/j.n epr.2006.03.003

[20] Watson, S. The support that mentors receive in the clinical setting. Nurse Education Today. 2000; 20(7): 585-592. PMID:12173263 http://dx.doi.org/10.1054/nedt. 2000.0463

[21] Lloyd, S. Modelling mentorship and collaboration for BSN and MSN students in a community clinical practicum. Journal of Nursing Education. 2006; 45(4): 129-132. PMID:16629281

[22] Jowett, R., McMullan, M. Learning in practice - practice educator role. Nurse Education in Practice. 2007; 7(4): 266-271. PMID:17689452 http://dx.doi.org/10.1016/j.nepr.2006 .08 .008

[23] Kenyon, L., Peckover, S. 'A juggling act': an analysis of the impact of providing clinical placements for pre-registration students on the organisation of community nursing and health visiting work. Nurse Education Today. 2008; 28(2): 202-209. PMID:17512096 http://dx.doi.org/10.1016/j.nedt.2007.03.014

[24] Robinson, S., Cornish, J., Driscoll, C., Knutton, S., Corben, V., Stevenson, T. Sustaining and managing the delivery of student nurse mentorship: roles, resources, standards and debates. Short report. Report for the NHS London 'Readiness for Work' programme. National Nursing Research Unit, King's College London. 2012. Available from: https://www.kcl.ac.uk/nursing/research /nnru/publications/Reports/Nurse-Mentorship-Repor t-Nov2012.pdf (lastaccessed15thAugust2014).

[25] Lynch, K.D. Modelling role enactment: Linking role theory and social cognition. Journal for the Theory of Social Behaviour. 2007; 37(4): 379-399. http://dx.doi.org/10.1111/j.1468-5914. $2007.00349 . x$

[26] Dierdorff, E. C. and Rubin, R. S. Carelessness and discriminability in work role requirement judgments: Influences of role ambiguity and cognitive complexity, Personnel Psychology. 2007; 60
(3): 597-625. http://dx.doi.org/10.1111/j.1744-6570.20 $07.00085 . x$

[27] Richer, M. C., Ritchie, J., Marchionni, C. Appreciative inquiry in health care. British Journal of Healthcare Management. 2010; 16(4): 164-172. http://dx.doi.org/10.12968/bjhc. 2010. 16.4. 47399

[28] Moody, R.C., Horton-Deutsch, S., Pesut, D.J. Appreciative inquiry for leading in complex systems: supporting the transformation of academic nursing culture.J Nurs Educ. 2007; 46(7): 319-324. PMID:17711069

[29] Reed, J., Richardson, E., Marais, S., Moyle, W. Older people maintaining well- being: an International Appreciative Inquiry study. International Journal of Older People Nursing. 2008; 3(1): 6875. PMID:20925893 http://dx.doi.org/10.1111/j.1748-3 743.2007.00111.x

[30] McAllister, K., Luckcock, T. Appreciative inquiry: a fresh approach to continuous improvement in public services. Housing, Care and Support. 2009; 12(1): 30-33. http://dx.doi.org/10.1108/146 08790200900006

[31] Meyer, J., Heath, H., Holman, C., Owen, T. Moving from victim blaming to an appreciative inquiry: exploring quality of life in care homes. Quality in Ageing and Older Adults. 2006; 7(4): 27-36. http://dx.doi.org/10.1108/14717794200600025

[32] Cooperrider, D.L., Whitney, D., Stavros, J.M. Appreciative Inquiry Handbook for Leaders of Change (2nd Edn) Ohio, Crown Publishing Inc. 2008; 5.

[33] Carter, B. 'One expertise among many' - working appreciatively to make miracles instead of finding problems: Using appreciative inquiry as a way of reframing research. Journal of Research in Nursing. $2006 ; 11(1)$ : 48-63. http://dx.doi.org/10.1177/17449 87106056488

[34] Linstone H.A., Turoff, M. The Delphi Method: Techniques and Applications. Addison-Wesley Publishing Company, Massachusetts. 1975.

[35] Powell, C. The Delphi technique: myths and realities. Journal of Advanced Nursing. 2003; 41(4): 376-38. PMID:12581103 http: //dx.doi.org/10.1046/j.1365-2648.2003.02537.x

[36] Patton, M. Qualitative Research and Evaluation Methods. Third edition. Thousand Oaks CA. Sage. 2002.

[37] Meyrick, J. What is good qualitative research? A first step towards a comprehensive approach to judging rigour/quality. Journal of Health Psychology. 2006; 11(5): 799-808. PMID:16908474 http://dx.doi.org/10.1177/1359105306066643

[38] Abbott, A. D. The system of profession: An essay on the division of expert labor. Chicago, University of Chicago Press. 1988.

[39] Maxwell, E., Baillie, L, McClaren, S., Rickard, W. Exploring the relationship between social identity and workplace jurisdiction for new nursing roles: A case study approach. International Journal of Nursing Studies. 2013; 50(5): 622-31. PMID:23199844 http: //dx.doi.org/10.1016/j.ijnurstu.2012.10.015

[40] Gillespie, M., McFetridge, B. Nurse education - the role of the nurse teacher. Journal of Clinical Nursing. 2006; 15(5): 639644. PMID:16629973 http://dx.doi.org/10.1111/j.1365-2 $702.2006 .01344 . x$

[41] Smith, P. The Emotional Labour of Nursing: Its Impact on Interpersonal Relations, Management and Educational Environment. London: Palgrave Macmillan. 1992.

[42] Gray, B. The emotional labour of nursing - Defining and managing emotions in nursing work. Nurse Education Today. 2009; 29(2): 168-175. PMID:18793817 http://dx.doi.org/10.1016 /j.nedt. 2008.08.003

[43] Francis, R. Report of the Mid Staffordshire NHS Foundation Trust Public Inquiry. 2013. Available from: http: //www . midstaff spublicinquiry . com/report (La staccessed15thAugust2014)

[44] Doody, O., Tuohy, D., Deasy, C. Final-year student nurses' perceptions of role transition. British Journal of Nursing. 2012; 21(11): 684-688. PMID:22875356 http://dx.doi.org/10.12 $968 /$ bjon. 2012.21 .11 .684 
[45] Duchscher, J.E.B. Transition shock: the initial stage of role adaptation for newly graduated Registered Nurses. Journal of Advanced Nursing. 2009; 65(5): 1103-1113. PMID:19183235 http://dx.d oi.org/10.1111/j.1365-2648.2008.04898.x

[46] Nash, R., Lemcke, P., Sacre, S. Enhancing transition: An enhanced model of clinical placement for final year nursing students. Nurse Education Today. 2009; 29(1): 48-56. PMID:18692279 http://dx .doi.org/10.1016/j.nedt.2008.06.004

[47] Shinyashiki, G.T., Mendes, I.A.C., Trevizan, M.A., Day, R.A. Professional socialization: students becoming nurses. Rev Latino-am Enfermagem. 2006; 14(4): 601-607. http://dx.doi.org/10.15 90/S0104-11692006000400019

[48] Mlinar, S. First and third year student nurses' perceptions of caring behaviours. Nursing Ethics. 2010; 17(4): 491-500. PMID:20610582 http://dx.doi.org/10.1177/0969733010364903

[49] Collington, V., Mallik, M., Doris, F., Fraser, D. Supporting the midwifery practice-based curriculum: The role of the link lecturer. Nurse Education Today. 2012; 32: 924-929. PMID:22051100 http://dx.doi.org/10.1016/j.nedt.2011.09.017

[50] Rooke, N. An evaluation of nursing and midwifery sign off mentor, new mentors and nurse lecturers' understanding of the sign off mentor role. Nurse Education in Practice. 2014; 14(1): $43-$ 48. PMID:23726744 http://dx.doi.org/10.1016/j.nepr. 20 13.04.015

[51] Zerwekh, J.V. The practice of presencing. Semin Oncol Nurs. 1997; 13(4): 260-2. http://dx.doi.org/10.1016/S0749-2081(97 ) $80022-8$
[52] Morrrell, N., Ridgway, V. Are we preparing student nurses for final practice placements? British Journal of Nursing. 2014; 23(10): 518523. http://dx.doi.org/10.12968/bjon.2014.23.10.518

[53] Keogh, B. Review into the quality of care and treatment provided by 14 hospital trusts in England: overview report. 2013. Available from: http://www.nhs.uk/NHSEngland/bruce-keogh-rev iew/Documents/outcomes/keogh-review-final-report. pdf (lastaccessed15thAugust2014).

[54] Girot, E.A. Preparing the practitioner for advanced academic study: the development of critical thinking. Journal of Advanced Nursing. 1995; 21(2): 387-394. PMID:7714299 http://dx.doi.org/10. $1111 / j .1365-2648.1995 . t b 02538 . x$

[55] Haith-Cooper, M. Problem-based learning within health professional education. What is the role of the lecturer? A review of the literature. Nurse Education Today. 2000; 20(4): 267272. PMID:10827097 http://dx.doi.org/10.1054/nedt.19 99.0397

[56] Gilmartin, J. Teachers' understanding of facilitation styles with student nurses. International Journal of Nursing Studies. 2001; 38: 481488. http://dx.doi.org/10.1016/S0020-7489(00)00085-7

[57] Allan, H.T. Using psychodynamic small group work in nurse education: Closing the theory-practice gap? Nurse Education Today. 2011; 31: 521-524. PMID:20951476 http://dx.doi.org/10.10 $16 / \mathrm{j}$. nedt .2010 .09 .006 